\title{
Maternal Plasma L-Carnitine Reduction During Pregnancy Is Mainly Attributed to OCTN2-Mediated Placental Uptake and Does Not Result in Maternal Hepatic Fatty Acid $\beta$-Oxidation Decline ${ }^{\text {[ }}$
}

\author{
Mengru Bai, Qingquan Zeng, Yingchun Chen, Mingyang Chen, Ping Li, Zhiyuan Ma, Dongli Sun, \\ Hui Zhou, Caihong Zheng, Su Zeng, and Huidi Jiang
}

Laboratory of Pharmaceutical Analysis and Drug Metabolism, College of Pharmaceutical Sciences (M.B., Y.C., M.C., P.L., Z.M., H.Z., S.Z., H.J.) and Women's Hospital, School of Medicine (Q.Z., D.S., C.Z.), Zhejiang University, Hangzhou, People's Republic of China

Received January 18, 2019; accepted March 22, 2019

\begin{abstract}
L-Carnitine (L-Car) plays a crucial role in fatty acid $\beta$-oxidation. However, the plasma L-Car concentration in women markedly declines during pregnancy, but the underlying mechanism and its consequences on maternal hepatic $\beta$-oxidation have not yet been clarified. Our results showed that the plasma L-Car level in mice at gestation day (GD) 18 was significantly lower than that in nonpregnant mice, and the mean fetal-to-maternal plasma L-Car ratio in GD 18 mice was 3.0. Carnitine/organic cation transporter 2 (OCTN2) was highly expressed in mouse and human placenta and upregulated as gestation proceeds in human placenta, whereas expressions of carnitine transporter (CT) 1, CT2, and amino acid transporter $\mathrm{B}^{0,+}$ were extremely low. Further study revealed that renal peroxisome proliferator-activated receptor $\alpha$ (PPAR $\alpha$ ) and OCTN2 were
\end{abstract}

downregulated and the renal L-Car level was reduced, whereas the urinary excretion of L-Car was lower in late pregnant mice than in nonpregnant mice. Meanwhile, progesterone (pregnancy-related hormone) downregulated the expression of renal OCTN2 via PPAR $\alpha$-mediated pathway, and inhibited the activity of OCTN2, but estradiol, corticosterone, and cortisol did not. Unexpectedly, the maternal hepatic level of L-Car and $\beta$-hydroxybutyrate (an indicator of mitochondrial $\beta$-oxidation), and mRNA levels of several enzymes involved in fatty acid $\beta$-oxidation in GD 18 mice were higher than that in nonpregnant mice. In conclusion, OCTN2 mediated L-Car transfer across the placenta played a major role in maternal plasma L-Car reduction during pregnancy, which did not subsequently result in maternal hepatic fatty acid $\beta$-oxidation decrease.

\section{Introduction}

L-Carnitine (L-Car) is a hydrophilic quaternary amine that plays a crucial role in fatty acid $\beta$-oxidation. L-Car and long-chain acyl CoA form acylcarnitines by the action of carnitine palmitoyltransferase 1 . Acylcarnitines are then translocated across the mitochondrial membrane by the carnitine/acylcarnitine translocase. Once inside mitochondria, carnitine palmitoyltransferase 2 removes L-Car from acylcarnitines and regenerates acyl-CoAs. L-Car then returns to the cytoplasm for another cycle while the acyl-CoAs enter $\beta$-oxidation (Ramsay et al., 2001; Foster, 2004). L-Car deficiency may cause fatty acid oxidation disorder, and lead to cardiomyopathy, muscle weakness, hypoglycemia, and fatty liver (Frigeni et al., 2017). The plasma concentration of L-Car in pregnant women is reported to be much lower than that in nonpregnant women and keeps declining as gestation proceeds (Winter et al., 1995; Lindsay et al., 2015). At the time of delivery, the maternal plasma L-Car

This work was supported by the National Natural Science Foundation of China [Grant 81573492, 81773804], and Zhejiang Province Natural Science Foundation of China [Grant LZ17H300001].

https//doi.org/10.1124/dmd.119.086439.

SThis article has supplemental material available at dmd.aspetjournals.org. concentration is only half of that in nonpregnant women, which will be returned to its original level 8 weeks after delivery (Cederblad et al., 1986; Cho and Cha, 2005). It seems that pregnancy leads to a reversible secondary deficiency of L-Car (Marzo et al., 1994). However, the reasons have not yet been clarified.

In humans, L-Car homoeostasis is maintained by dietary absorption, endogenous synthesis, and efficient renal reabsorption (Vaz and Wanders, 2002). About $75 \%$ of the L-Car requirement is provided by diet, whereas $25 \%$ is synthesized endogenously in the liver and kidney of adults. L-Car is eliminated in its original form by glomerular filtration in humans; however, most of the filtered L-Car will be reabsorbed in kidney by carnitine transporters (CTs), especially by carnitine/organic cation transporter (OCTN) 2 (SLC22A5 gene), a high-affinity L-Car transporter located in the apical side of renal tubular epithelial cells (Longo et al., 2016). A defect in the OCTN2 will cause urinary L-Car wasting and subsequently will result in primary L-Car deficiency (Lahjouji et al., 2002). Besides OCTN2, CT1 (SLC22A15 gene), CT2 (SLC22A16 gene), and amino acid transporter $\mathrm{B}^{0,+}\left(\mathrm{ATB}^{0,+}\right.$; SLC6A14 gene) can also mediate L-Car uptake (Sekine et al., 1998; Nakanishi et al., 2001; Enomoto et al., 2002). Therefore, CTs in the kidney are very important for the L-Car homeostasis.

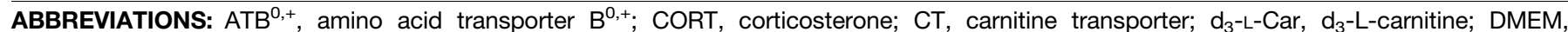
Dulbecco's modified Eagle's medium; E2, estradiol; GAPDH, glyceraldehyde-3-phosphate dehydrogenase; GD, gestation day; hOCTN, human carnitine/organic cation transporter; L-Car, L-carnitine; LD, lactation day; MDCK, Madin-Darby canine kidney; OCTN, carnitine/organic cation transporter; P4, progesterone; PPAR, peroxisome proliferator-activated receptor; qRT-PCR, quantitative real-time polymerase chain reaction; TC, total cholesterol; TG, triglyceride; WY14643, 4-chloro-6-(2,3-xylidino)-2-pyrimidinylthioacetic acid. 
A series of physiologic changes, including increased maternal fat, blood volume, cardiac output, and blood flow to the kidneys, occur in pregnant women (Costantine, 2014). In addition, the plasma concentrations of several hormones are gradually increased during pregnancy. The plasma levels of estradiol (E2) and progesterone (P4) in pregnant women during the third trimester will reach tens to hundreds folds of the original levels (La Marca et al., 2005; Zhang et al., 2015). And the plasma concentrations of glucocorticoids (cortisol in humans and corticosterone [CORT] in rodents) are also gradually increased during pregnancy (Soldin et al., 2005; Jung et al., 2011).

It is noteworthy that the placenta mediates maternofetal transport of a variety of nutrients, including L-Car. L-Car is pivotal for the fetal organism, but the fetus has a limited capacity for L-Car biosynthesis (Hahn, 1981; Shenai and Borum, 1984); thus, the fetus obtains almost all of the required L-Car from the maternal circulation. And the L-Car level in umbilical cord plasma is reported to be higher than that in the mother (Talián et al., 2007; Keller et al., 2009). We hypothesized that it might be one of the reasons for the reduction of maternal plasma L-Car concentration during pregnancy. It has been reported that OCTN2, which is located in the apical membrane of syncytiotrophoblasts of the human placenta, mediates the placental transport of L-Car (Lahjouji et al., 2004; Grube et al., 2005); however, it is not clear whether other CTs are involved in the process.

It was known that plasma lipid levels, including those of triglyceride (TG) and total cholesterol (TC), were markedly higher in pregnant women than those in nonpregnant women, and were increased as gestation proceeds (Alemu et al., 2018; Wang et al., 2018). Compared with healthy control subjects, the levels of TG and TC were much higher in women with preeclampsia, gestational diabetes mellitus, and intrahepatic cholestasis of pregnancy (Pecks et al., 2016; Layton et al., 2019). However, the mechanism also remains unknown.

Based on the above information, we hypothesized that L-Car deficiency during pregnancy might induce hepatic fatty acid oxidation disorder, and subsequently lead to the increase of plasma lipid levels. Therefore, one aim of the present study was to elucidate a possible mechanism for the reduction of maternal plasma L-Car concentration during gestation; the other aim was to explore whether such a low L-Car concentration was associated with the rise of plasma lipid levels in pregnancy.

\section{Materials and Methods}

Materials. FBS, trypsin, Dulbecco's modified Eagle's medium (DMEM) and DMEM/F12 were purchased from Thermo Fisher Scientific (Waltham, MA). L-Car was purchased from Dalian Meilun Biotechnology Co., Ltd. (Dalian, People's Republic of China). L-Car (methyl- $\left.\mathrm{d}_{3}\right)\left(\mathrm{d}_{3}\right.$-L-Car) was obtained from Cambridge Isotope Laboratories, Inc. (Tewksbury, MA). E2, P4, cortisol, and WY14643 [4-chloro-6-(2,3-xylidino)-2-pyrimidinylthioacetic acid] were purchased from Aladdin Biochemical Technology Co., Ltd. (Shanghai, People's Republic of China). CORT was obtained from TCI (Shanghai) Development Co., Ltd. (Shanghai, People's Republic of China). OCTN2 antibody (catalog \#SAB4300885; species reactivity: human, mouse, rat) was obtained from SigmaAldrich (St. Louis, MO). Glyceraldehyde-3-phosphate dehydrogenase (GAPDH) antibody and the secondary anti-rabbit and anti-mouse antibodies were obtained from Multisciences (Lianke) Biotech Co., Ltd. (Hangzhou, People's Republic of China). Acetonitrile was obtained from Tedia (Fairfield, OH). Ammonium acetate and formic acid were obtained from Sigma-Aldrich. All other chemicals or solvents were of the highest grade commercially available.

Animal Experiments. All animal procedures were performed in accordance with the Public Health Service Policy on Humane Care and Use of Laboratory Animals (http://grants1.nih.gov/grants/olaw/references/phspol.htm) and were approved by the Institutional Animal Care and Use Committee of Zhejiang University (2015-0026). All experimental procedures were conducted as humanely as possible.
Specific pathogen-free female nonpregnant and pregnant (gestation day [GD] 14) ICR mice, 8-10 weeks of age, were obtained from Beijing Vital River Laboratory Animal Technology Co., Ltd. (certificate number SCXK 2016-0011; Beijing, People's Republic of China). The animals were housed in cages at controlled temperature $\left(22.0 \pm 1{ }^{\circ} \mathrm{C}\right)$ and humidity $(50 \pm 10) \%$ with a 12 -hour light/dark cycle and free access to food and water throughout the study. Mice consumed ad libitum a commercial standard mouse diet (Laboratory Rodent Diet 5001; LabDiet, St. Louis, MO). No dietary manipulations were otherwise conducted, and all dietary conditions were the same for the control and treated groups.

Blood, livers, kidneys, hearts, and muscles of the nonpregnant $(n=10)$ and pregnant (GD 18, $n=10$ ) mice were collected after cervical dislocation, and the fetal blood samples were collected immediately after fetuses were sacrificed by decapitation. The plasma/serum was collected immediately after centrifugation at $8000 \mathrm{~g}$ for 10 minutes and stored at $-40^{\circ} \mathrm{C}$ until analysis. Placentas of the pregnant mice at GD $15(n=8)$ and GD $18(n=8)$ were collected, and the tissues were frozen in liquid nitrogen immediately after dissection and stored at $-80^{\circ} \mathrm{C}$ until analysis.

Other nonpregnant mice ( $n=10$, two mice per cage) and pregnant mice ( $n=5$, one mouse per cage) were used in the urine excretion study. On GD 16-18 and lactation day (LD) 8-10, urine samples within 24 hours from pregnant or postpartum mice were collected. On another successive 3-day period (days 1-3), urine samples were collected within 24 hours from nonpregnant mice.

The concentrations of L-Car in plasma, tissues, and urine were determined by the liquid chromatography-tandem mass spectroscopy method described previously (Wang et al., 2019). The mRNA and protein levels of related genes in the liver, kidney, and placenta were measured by quantitative real-time polymerase chain reaction (qRT-PCR) and Western blot. The concentrations of $\beta$-hydroxybutyrate in serum and liver were determined using a $\beta$-Hydroxybutyrate Test Kit (Colorimetric Method) (Ningbo Ruiyuan Biotechnology Co., Ltd, Ningbo, People's Republic of China).

Cell Culture. Parental Madin-Darby canine kidney (MDCK) cells were obtained from Peking Union Medical College (Beijing, Republic of China). MDCK-human OCTN (hOCTN) 2 cells (MDCK cells stably transfected with plasmid pcDNA3.1 [+] vector containing human OCTN2 cDNA) were constructed in our laboratory (Li et al., 2017). Cells were cultured in DMEM supplemented with 10\% FBS and $1 \%$ penicillin/streptomycin at $37^{\circ} \mathrm{C}$ with $5 \%(\mathrm{v} / \mathrm{v}) \mathrm{CO}_{2}$. $\mathrm{HK}-2$ cells were kindly provided by Stem Cell Bank, Chinese Academy of Sciences and maintained in DMEM/F-12 medium with $10 \% \mathrm{FBS}$ and $1 \%$ penicillin/streptomycin in a humidified $5 \%(\mathrm{v} / \mathrm{v}) \mathrm{CO}_{2}$ air atmosphere at $37^{\circ} \mathrm{C}$.

Cellular Accumulation Experiment. MDCK-hOCTN2 cells were seeded into 24 -well plates at a density of $2 \times 10^{5}$ /well. On day 3 after seeding, cellular accumulation experiments were performed with the method described by our laboratory (Bai et al., 2017; Ma et al., 2017). Cells were washed twice and preincubated with Krebs-Ringer-Henseleit buffer for 10 minutes at $37^{\circ} \mathrm{C}$, then $200 \mu \mathrm{l}$ of Krebs-Ringer-Henseleit buffer containing

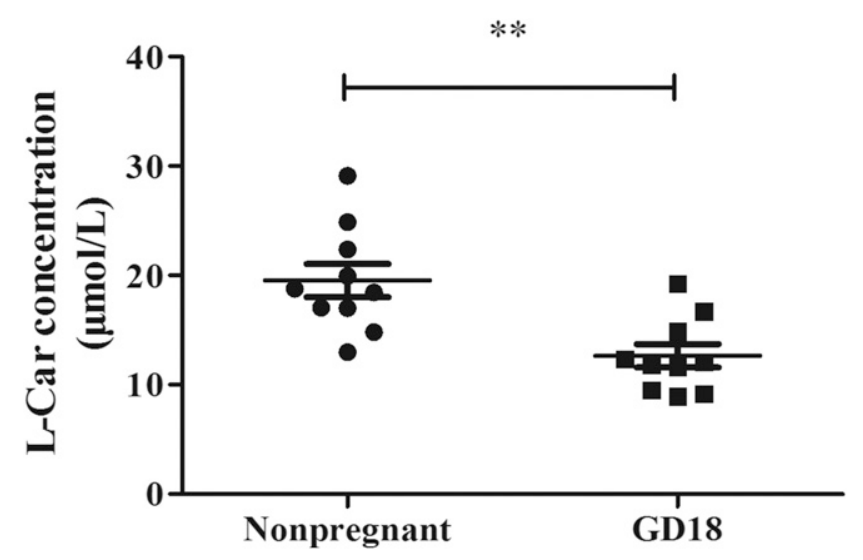

Fig. 1. The concentration of L-Car in plasma of nonpregnant and pregnant mice at GD 18. Data are expressed as the mean \pm S.E.M., $n=10$. Compared with the nonpregnant group, ${ }^{* * P}<0.01$. 
$\mathrm{d}_{3}$-L-Car with or without pregnancy-related hormones (E2, P4, CORT, and cortisol) was added to initiate accumulation for 3 minutes. Accumulation was terminated by removing the incubation buffer and immediately adding ice-cold buffer. Finally, cells were washed three times with ice-cold buffer and lysed with $100 \mu \mathrm{l}$ of $0.1 \%$ SDS. The accumulation assay in HK-2 cells was similar to that in MDCK-hOCTN2 cells. The concentration of $\mathrm{d}_{3}-\mathrm{L}-\mathrm{Car}$ was measured using liquid chromatography-tandem mass spectroscopy with the method described previously (Wang et al., 2019).
Treatment of HK-2 Cells with Hormones. HK-2 cells were seeded at a density of $4 \times 10^{5} /$ well in 12-well plates. After overnight treatment, cells were treated with or without designated concentrations of E2, P4, CORT, or cortisol for 24 hours (refreshing the medium every 12 hours), then the concentration of L-Car or mRNA expression of OCTN2 was measured. To investigate the role of peroxisome proliferator-activated receptor (PPAR) $\alpha$ in OCTN2 expression, the cells were incubated with $100 \mu \mathrm{M}$ WY14643 (a PPAR $\alpha$ agonist) under $20 \mu \mathrm{M}$ P4 treatment.
A

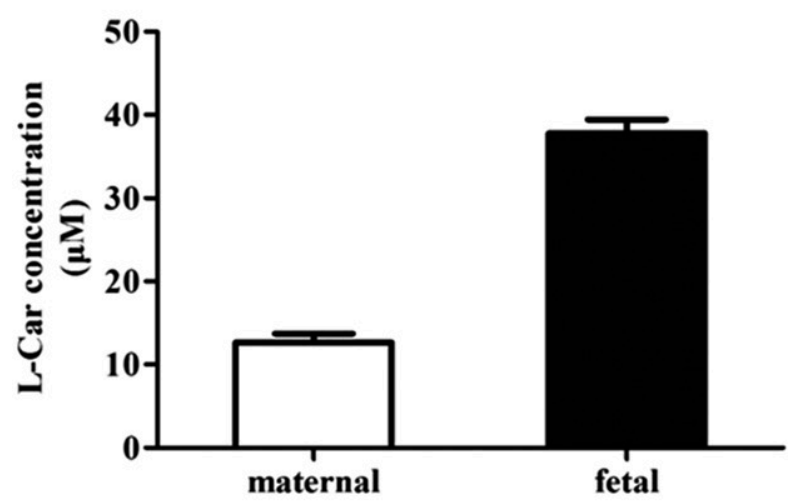

C

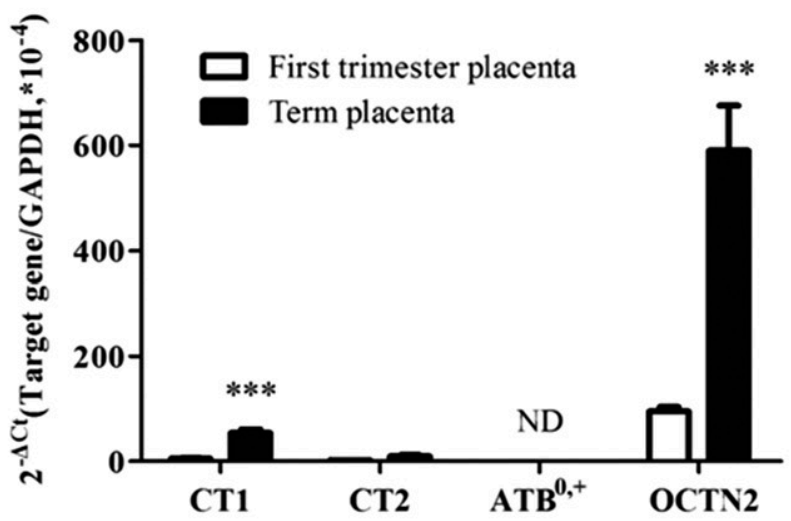

E

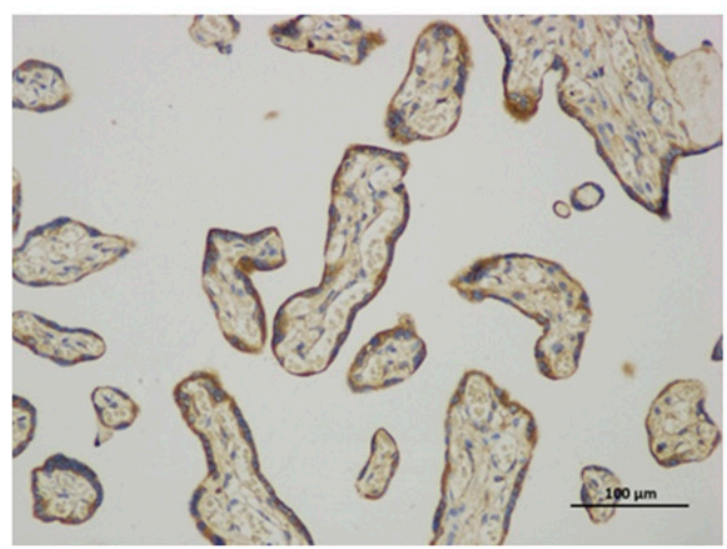

B

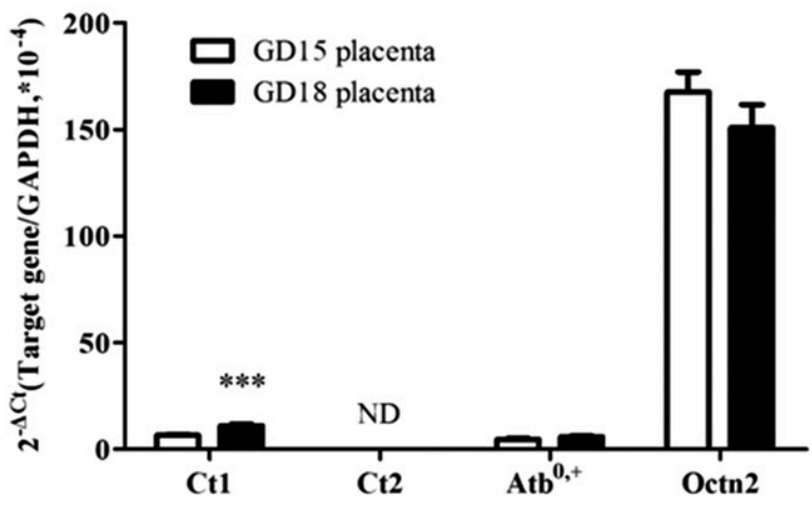

D
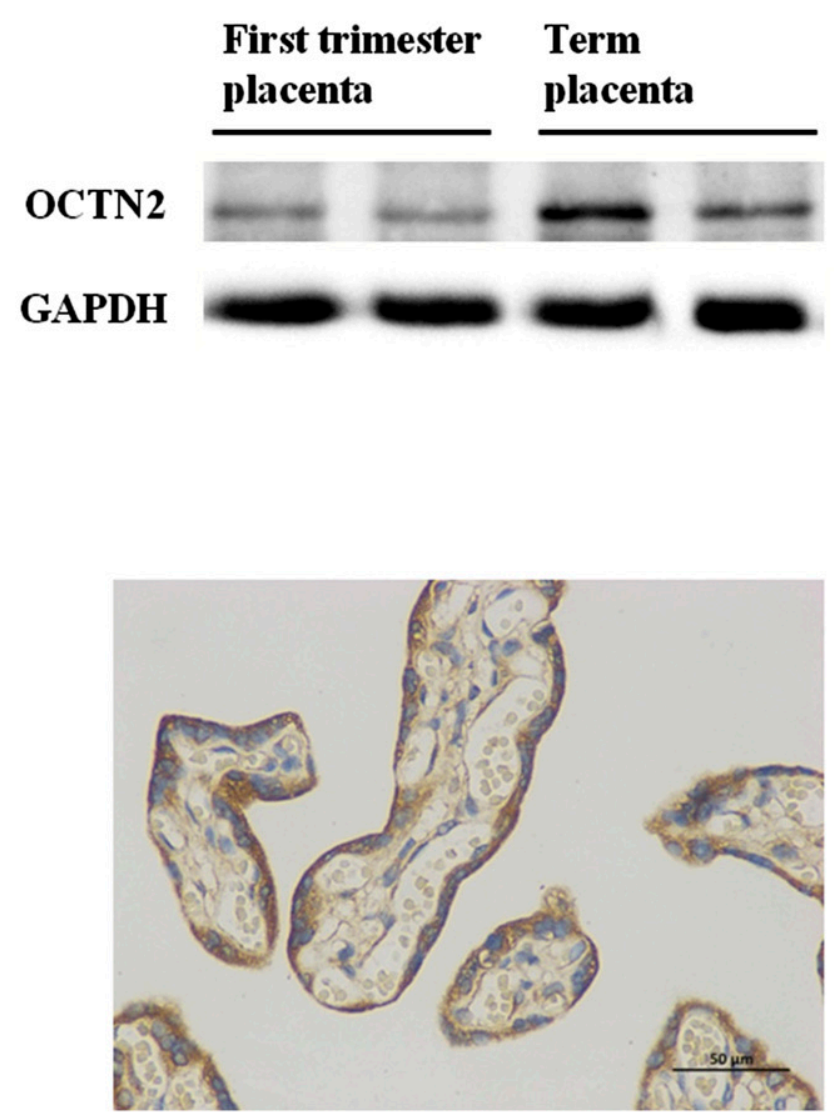

Fig. 2. (A) The concentration of L-Car in maternal and fetal plasma of mice at GD 18. Data are expressed as the mean \pm S.E.M., $n=10$. (B) The mRNA level of CTs in mouse placenta at GDs 15 and 18. Data are expressed as the mean \pm S.E.M., $n=8$. Compared with the GD 15 placenta, $* * * P<0.001$. The mRNA level of CTs (C) and protein level of OCTN2 (D) in the first-trimester placenta and term human placenta. Data are expressed as the mean \pm S.E.M. $(n=32$ for first trimester placenta; and $n=23$ for term placenta). Compared with the first trimester placenta, $* * * P<0.001$. ND, not detected. (E) Immunohistochemical detection of OCTN2 in the human term placenta. Original magnification, $200 \times$ in left panel, and $400 \times$ in right panel. 
Clinical Tissue Collection. All the human placentas were obtained from uncomplicated pregnancies in accordance with the ethical standards of Women's Hospital, School of Medicine, Zhejiang University. All the participants provided written informed consent. Term placentas $(n=23)$ were collected after natural delivery at term (38-40 weeks of gestation), and the first-trimester placentas $(n=32)$ were acquired from the interruption of the pregnancy at between 8 and 10 weeks of gestation. For qRT-PCR and Western blot, the placental samples were frozen in liquid nitrogen immediately after delivery or surgery and stored at $-80^{\circ} \mathrm{C}$ until analysis. For immunohistochemistry, placental tissue sections were obtained by dissecting a segment $\left(1.5 \mathrm{~cm}^{2}, 0.5 \mathrm{~cm}\right.$ thick) from the maternal part of the placenta and were fixed in $4 \%$ formaldehyde at $4{ }^{\circ} \mathrm{C}$ for 2 days, and paraffin sections of $2 \mu \mathrm{m}$ were generated.

qRT-PCR Assay. Total RNA was extracted from tissues and cells using RNAsimple Total RNA Kit (DP419; Tiangen Biotech (Beijing) Co., Ltd., Beijing People's Republic of China). Then cDNA was synthesized according to the manufacturer protocol using PrimeScript RT Master Mix (TaKaRa, Tokyo, Japan). The resulting cDNA was amplified by qRT-PCR with SYBR Premix Ex Taq (TaKaRa). Relative mRNA levels of target genes were normalized by $\mathrm{GAPDH}$, using the $\Delta \mathrm{Ct}$ method and described as $2^{-\Delta \mathrm{Ct}}, \Delta \mathrm{Ct}=$ average $\mathrm{Ct}$ (target gene) - average $\mathrm{Ct}$ (GAPDH). To determine the fold change of target genes, results were calculated using the $\Delta \Delta \mathrm{Ct}$ method and described as $2^{-\Delta \Delta \mathrm{Ct}}, \Delta \Delta \mathrm{Ct}=$ (average $\mathrm{Ct}$ [target gene] - average $\mathrm{Ct}$ [GAPDH]) sample - (average Ct [target gene] - average $\mathrm{Ct}[\mathrm{GAPDH}])_{\text {control }}$. The specific primers are shown in Supplemental Table 1.

Western Blot Analysis. Tissues were homogenized in radio immunoprecipitation assay lysis buffer (Beyotime Biotechnology, Shanghai, People's Republic of China), and the protein concentration was determined with a BCA Protein
Assay Kit (Beyotime Biotechnology). Proteins were mixed with loading buffer (P0015; Beyotime Biotechnology, Shanghai, People's Republic of China) and then boiled at $100^{\circ} \mathrm{C}$ for 5 minutes. Aliquots of denatured protein were separated by SDS-PAGE (Bio-Rad, Hercules, CA) and subsequently transferred onto polyvinylidene fluoride membrane (Millipore, Burlington, MA). The membranes were blocked and incubated with primary anti-OCTN2 antibody (1:1000) or antiGAPDH antibody (1:5000) for 4 hours at room temperature. Membranes were then washed with Tris-buffered saline/Tween 20 three times ( 5 minutes every time) and incubated with horseradish peroxidase-conjugated secondary antibodies at room temperature for 2 hours. After being washed with Tris-buffered saline/Tween 20 again three times ( 5 minutes every time), signals were visualized by chemiluminescent detection using the enhanced chemiluminescence Western blotting detection system (LI-COR, Lincoln, NE).

Immunohistochemistry. The slides were deparaffinized in xylene and rehydrated in a series of graded alcohols. After quenching endogenous peroxidase activity with $1 \% \mathrm{H}_{2} \mathrm{O}_{2}$, the sections were rinsed with PBS and incubated with 5\% bovine serum albumin for 30 minutes at room temperature to reduce nonspecific binding, then for 16 hours at $4{ }^{\circ} \mathrm{C}$ with anti-OCTN2 antibody (1:50) diluted in 5\% bovine serum albumin. The section was incubated with biotinylated anti-rabbit $\mathrm{IgG}$ antibody for 1 hour at room temperature, washed, then incubated with streptavidin peroxidase for 1 hour at room temperature, and was followed by interaction with the 3,3-diaminobenzidine liquid substrate system (SigmaAldrich) for 1 minute. All sections were counterstained with hematoxylin for 3 minutes.

Data Analysis. Data are expressed as the mean \pm S.E.M. In vitro experiments were conducted at least two times in triplicate. $\mathrm{IC}_{50}$ values were assessed by nonlinear regression using GraphPad Prism 5.0 (GraphPad Software, San Diego,

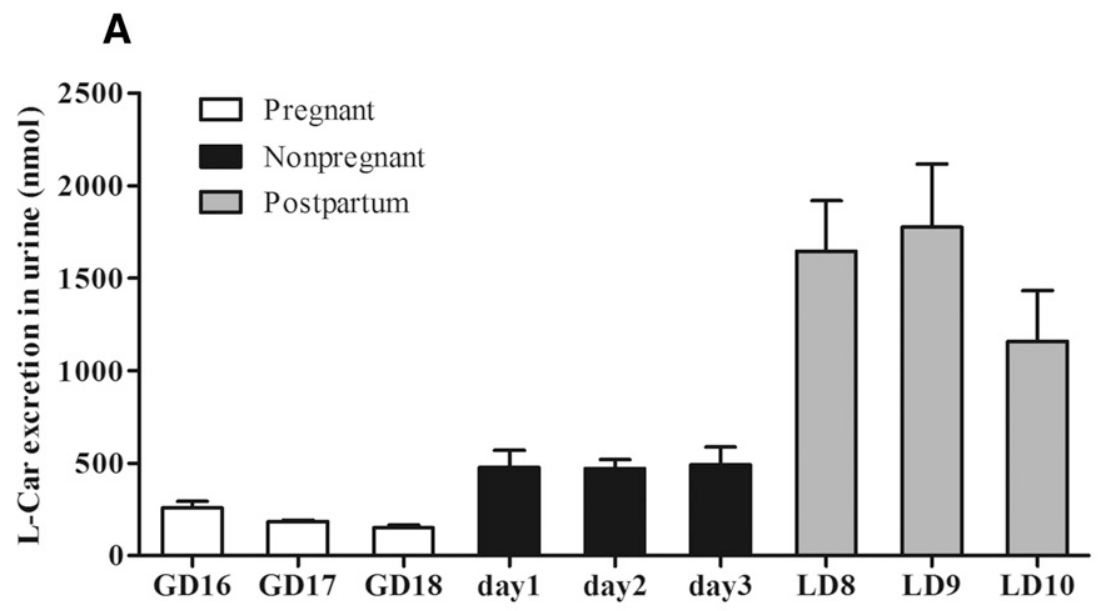

B

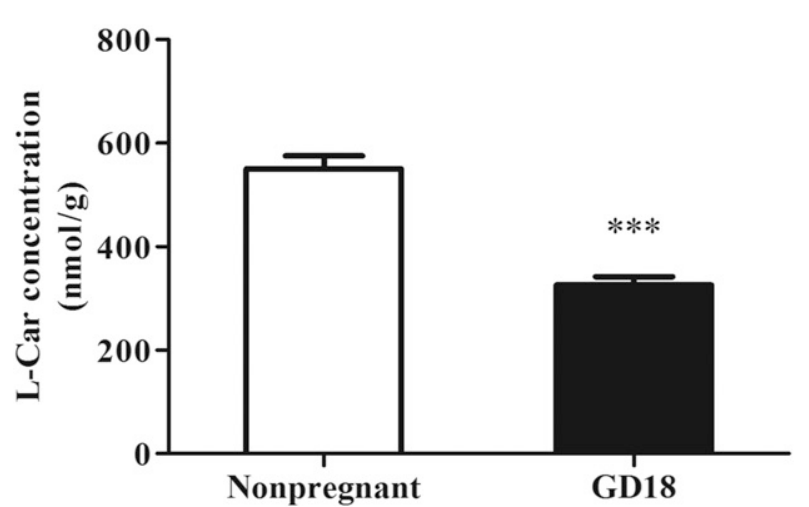

C

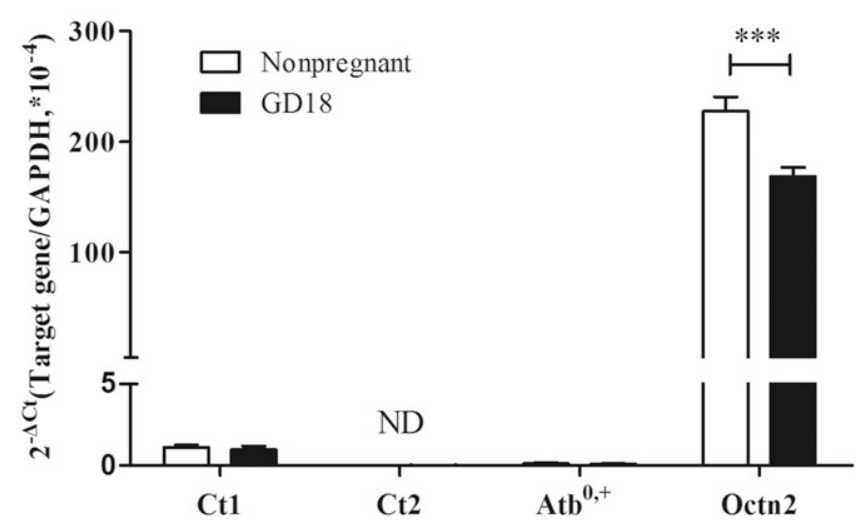

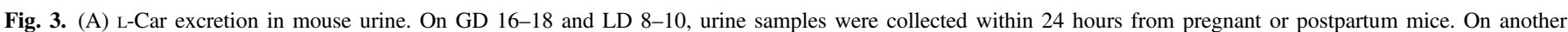

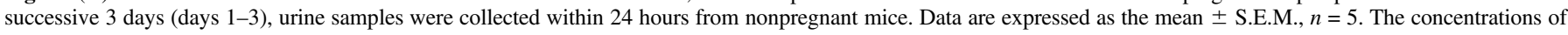

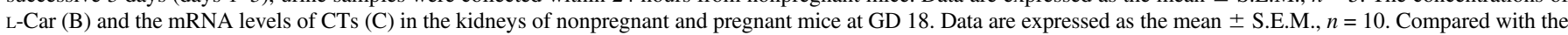
nonpregnant group, $* * * P<0.001$. 
CA). Student's $t$ test was used to compare differences between two groups, whereas one-way analysis of variance with the Dunnett's test was applied for data with more than two groups. $P$ values $<0.05$ were considered to be statistically significant.

\section{Results}

The Maternal Plasma L-Car Concentration Decreased in Pregnant Mice. In nonpregnant mice, the plasma L-Car concentration was about $19.5 \mu \mathrm{M}$; however, it was sharply reduced to $12.6 \mu \mathrm{M}$ in pregnant mice at GD $18(P<0.01)$ (Fig. 1).

Reduction of Maternal Plasma L-Car Level Might Be Attributed to High Placental Transfer via OCTN2. To clarify the reason for maternal plasma L-Car reduction in pregnant mice, we measured the concentrations of L-Car in the maternal and fetal plasma. As shown in Fig. 2A, the mean concentrations of L-Car were $12.6 \mu \mathrm{M}$ in maternal plasma and $37.8 \mu \mathrm{M}$ in fetal plasma, respectively. The mean fetalto-maternal plasma concentration ratio of L-Car in GD 18 mice was 3.0. Since placental transfer of L-Car is mediated mainly by CTs, we detected the mRNA levels of Ct1, Ct2, Octn2, and $\mathrm{Atb}^{0,+}$ in the placenta of pregnant mice at GDs 15 and 18 (Fig. 2B). Our results revealed that Octn2 was highly expressed in mouse placenta, but no difference was found between mice at GD 15 and GD 18. The mRNA levels of Ct1 and $\mathrm{Atb}^{0,+}$ were extremely low in mouse placenta, whereas $\mathrm{Ct} 2$ was undetectable. The above data imply that OCTN2 plays a key role in placental transfer of L-Car.

We further detected the mRNA expression of CTs in human placenta. As shown in Fig. 2C, OCTN2 was highly expressed, whereas the expression levels of CT1 and CT2 were very low and $\mathrm{ATB}^{0,+}$ was undetected. The mRNA and protein expression of OCTN2 in the term placenta were obviously higher than those in the first trimester placenta (Fig. 2D). The immunohistochemical results showed that OCTN2 was expressed on the maternal side of syncytiotrophoblasts of the human term placenta (Fig. 2E). Therefore, OCTN2 also plays a crucial role in L-Car transfer across human placenta.

Reduction of Maternal Plasma L-Car Level Might Not Be Attributed to Renal Excretion Increase. L-Car is excreted into urine by glomerular filtration; however, most of the filtered L-Car is reabsorbed in proximal tubules via transporters. Thus, a decrease in renal reabsorption of $\mathrm{L}-\mathrm{Car}$ will also lead to a reduction in plasma L-Car. However, the urinary excretion of L-Car in pregnant mice during the third trimester (GD 16-18) was tremendously lower than that in nonpregnant mice (days 1-3), whereas the excretion largely increased after delivery (LD 8-10) (Fig. 3A). The results indicate that the decreased concentration of L-Car in maternal plasma of pregnant mice in the third trimester is not attributed to urinary excretion increase.

The concentration of L-Car in the kidneys of GD 18 mice (326 nmol/g) was significantly lower than that in nonpregnant mice $(551 \mathrm{nmol} / \mathrm{g})(P<0.001)$ (Fig. 3B). Moreover, the mRNA level of Octn 2 in the kidney of GD 18 mice was approximately $72 \%$ of that in nonpregnant mice $(P<0.001)$, whereas the mRNA expressions of other CTs, including $\mathrm{Ct} 1, \mathrm{Ct} 2$, and $\mathrm{Atb}^{0,+}$, were very low in the kidney (Fig. 3C). The results suggest that renal reabsorption of L-Car is decreased in late pregnancy due to downregulated OCTN2 in the kidney.
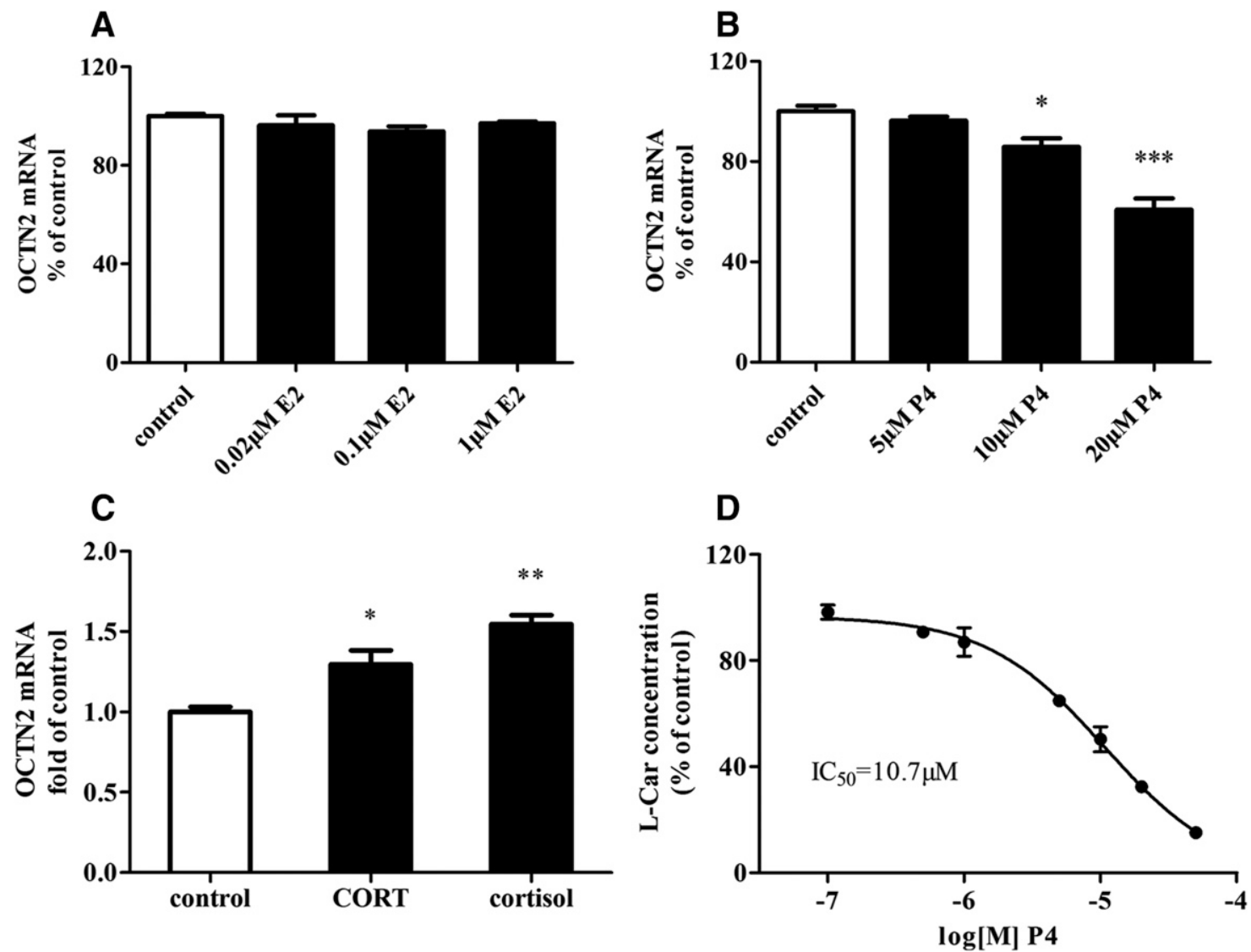

Fig. 4. The effect of E2 (A), P4 (B), and $10 \mu \mathrm{M}$ CORT and cortisol (C) on the mRNA expression of OCTN2 in HK-2 cells, and the concentration of L-Car in HK-2 cells in response to P4 (D) treatment. Cells were incubated with or without designated concentrations of hormones for 24 hours. Data are expressed as the mean \pm S.E.M. from two independent experiments conducted in triplicate. Compared with the control, $* P<0.05 ; * * P<0.01 ; * * * P<0.001$. 
OCTN2 Expression was Downregulated by P4 in HK-2 Cells. To investigate the reason why renal Octn2 was downregulated in GD 18 mice, we further explored whether pregnancy-related hormones, including E2, P4, CORT, and cortisol, had an effect on OCTN2 expression in HK-2 cells (a normal human proximal tubule epithelial cell line). P4 (5-20 $\mu \mathrm{M})$ concentration-dependently downregulated the mRNA level of OCTN2, whereas E2 did not show any effect (Fig. 4, A and B). However, $10 \mu \mathrm{M}$ CORT and cortisol upregulated the mRNA level of OCTN2 in HK-2 cells (Fig. 4C). In addition, P4 reduced the concentration of L-Car in $\mathrm{HK}-2$ cells with an $\mathrm{IC}_{50}$ value of $10.7 \mu \mathrm{M}$ (Fig. 4D).

P4-Induced Downregulation of OCTN2 Was Probably through Downregulation of PPAR $\alpha$ but Not PPAR $\gamma$. It has been reported that PPAR $\alpha$ and PPAR $\gamma$ contributed to OCTN2 regulation (D'Argenio et al., 2010; Luo et al., 2014, 2016). To determine whether PPAR $\alpha / \gamma$ contributed to P4-induced OCTN2 downregulation, we examined the mRNA expression of PPAR $\alpha / \gamma$ in HK- 2 cells with or without P4 treatment. P4 (5-20 $\mu \mathrm{M})$ downregulated the mRNA level of PPAR $\alpha$ in a concentration-dependent manner, whereas the PPAR $\gamma$ expression was not markedly altered (Fig. 5, A and B). Furthermore, WY14643 (100 $\mu \mathrm{M})$, a PPAR $\alpha$ agonist, blocked $20 \mu \mathrm{M}$ P4-induced downregulation of OCTN2 as well as PPAR $\alpha$ in HK-2 cells $(P<0.001)$ (Fig. 5, C and D). Additionally, the mRNA level of Ppar $\alpha$ was also obviously lower in the kidneys of GD 18 mice than that in nonpregnant mice $(P<0.05)$ (Fig. 5E). The above results suggest that P4 downregulates the expression of OCTN2 in HK-2 cells through a PPAR $\alpha$-mediated pathway.

P4 Inhibited OCTN2 Mediated $\mathbf{d}_{3}$-L-Car Uptake. To determine whether pregnancy-related hormones inhibit the L-Car uptake mediated by OCTN2, the accumulation of $\mathrm{d}_{3}$-L-Car in MDCK-hOCTN2 cells was evaluated in the absence or presence of E2, P4, CORT, or cortisol. Our data demonstrated that $\mathrm{P} 4$ reduced the accumulation of $\mathrm{d}_{3}$-L-Car in a concentration-dependent manner with an $\mathrm{IC}_{50}$ value of $15.8 \mu \mathrm{M}$, whereas E2 did not (Fig. 6, A and B). A high concentration $(100 \mu \mathrm{M})$ of CORT and cortisol slightly inhibited the uptake of $\mathrm{d}_{3}$-L-Car in MDCK-hOCTN2 cells $(P<0.001)$ (Fig. 6C). Similarly, P4 (10 and $50 \mu \mathrm{M})$ significantly reduced the uptake of $\mathrm{d}_{3}$-L-Car in HK-2 cells $(P<0.001)$ (Fig. 6D).

$\beta$-Oxidation of Fatty Acids in the Liver of GD 18 Mice Was Higher than That in Nonpregnant Mice. Although the concentration of L-Car in maternal plasma was much lower in GD 18 mice than that in nonpregnant mice (Fig. 1), the L-Car concentration in the liver of GD 18 mice was significantly higher than that in nonpregnant mice $(P<0.01)$ (Fig. 7A). Similarly, the hepatic level of $\beta$-hydroxybutyrate, an indicator of mitochondrial $\beta$-oxidation, was also obviously higher in GD 18 mice than that in nonpregnant mice $(P<0.001)$ (Fig. 7B), whereas the serum level was not markedly altered $(P>0.05)$ (Fig. 7C). To further elucidate the mechanism of hepatic $\beta$-hydroxybutyrate increase, the mRNA levels of key enzymes involved in fatty acid $\beta$-oxidation were measured. As shown in Fig. 7D, the long-chain acylCoA synthetase 1 and carnitine palmitoyltransferase 1a in the liver were obviously upregulated in GD 18 mice compared with nonpregnant mice $(P<0.01)$; however, the expressions of other genes were not changed $(P>0.05)$. In addition, the enzymes involved in $\beta$-hydroxybutyrate synthesis, such as hydroxymethyl glutaryl-CoA synthase and hydroxymethyl glutaryl-CoA lyase, were significantly increased in the liver of GD 18 mice $(P<0.01)$, whereas 3-hydroxybutyrate dehydrogenase 1 decreased $(P<0.05)$ (Fig. 7E). These results suggest that $\beta$-oxidation of
A

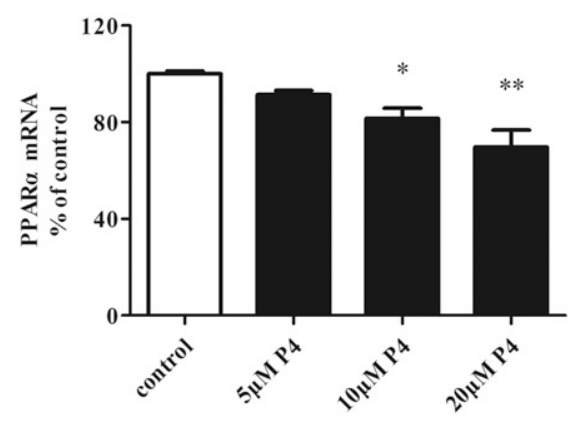

B

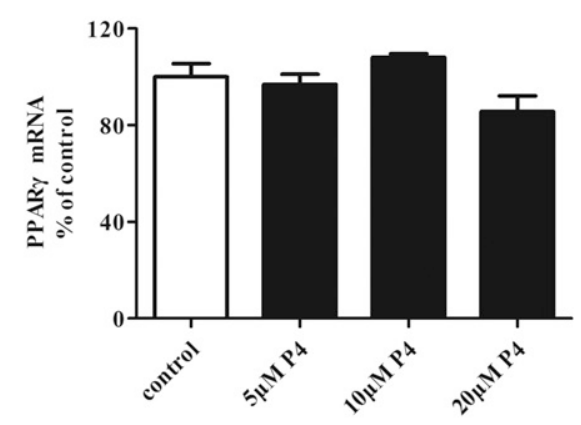

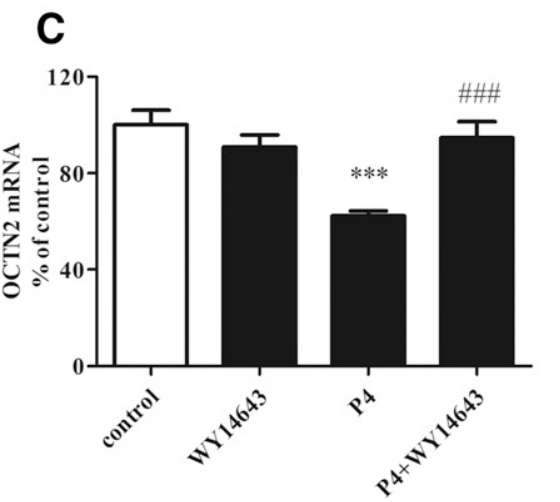
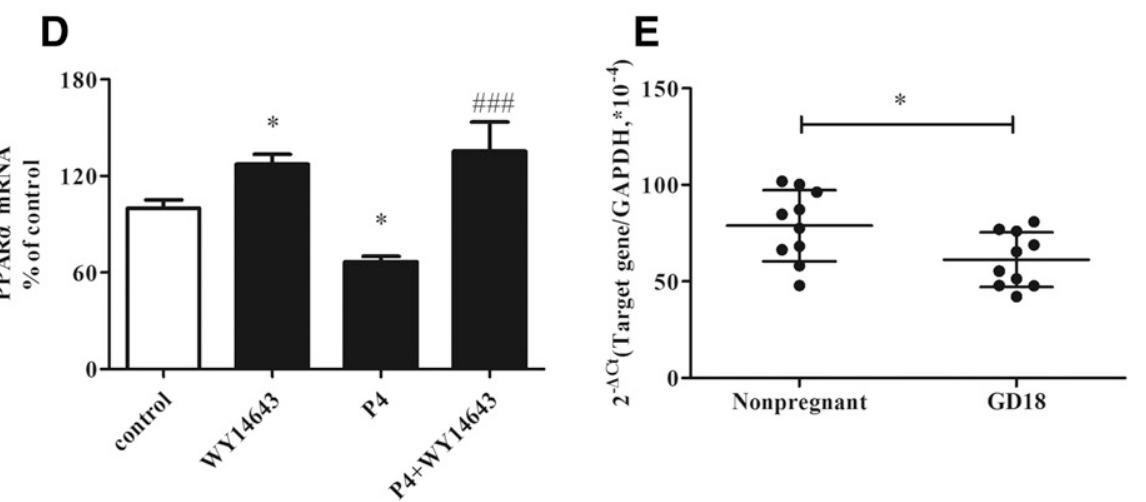

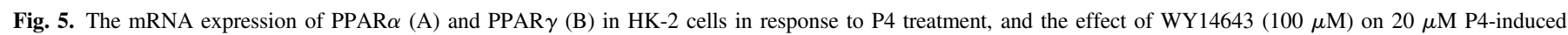

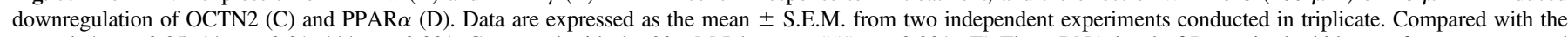

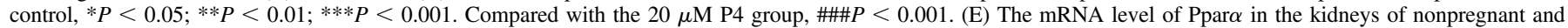
pregnant mice at GD 18. Data are expressed as the mean \pm S.E.M., $n=10$. Compared with the nonpregnant group, $* P<0.05$. 
A

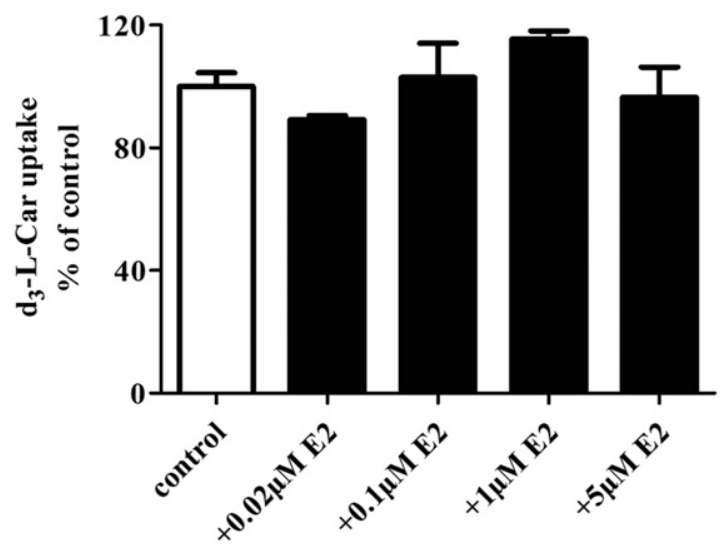

C

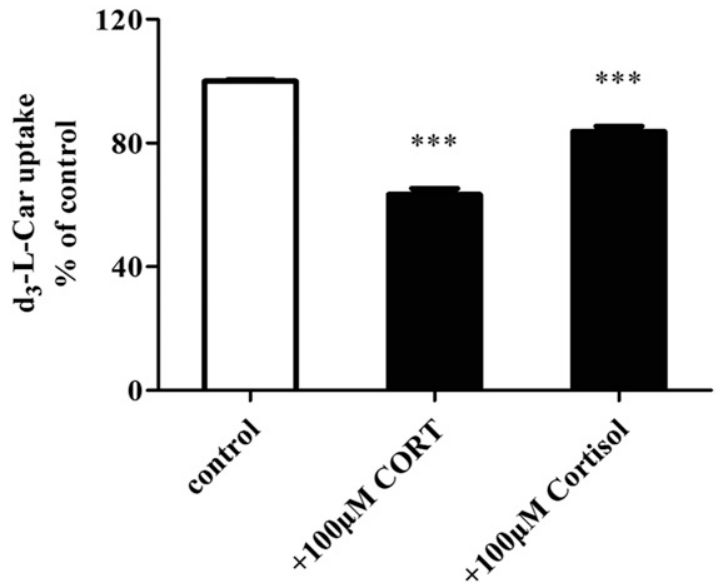

B

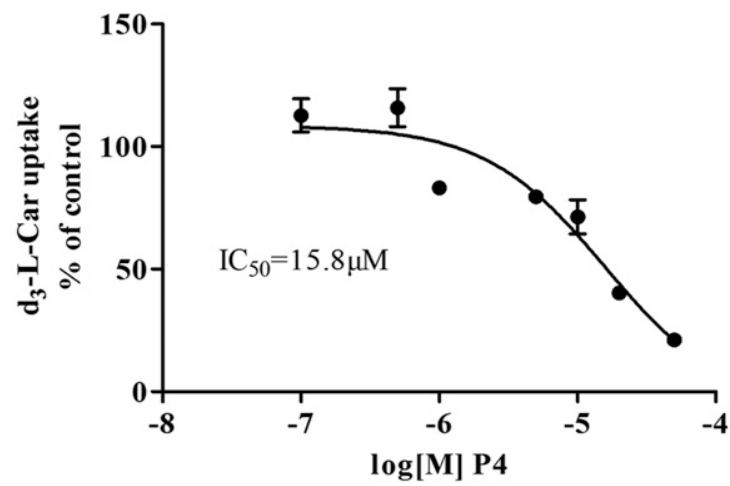

D

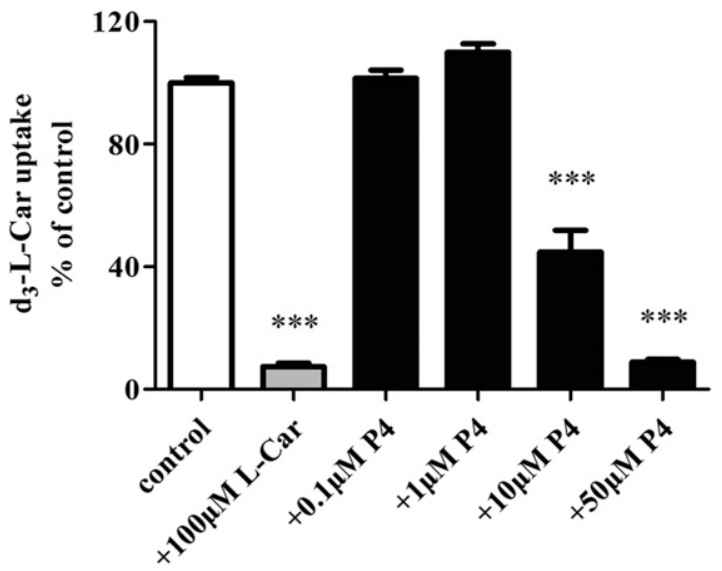

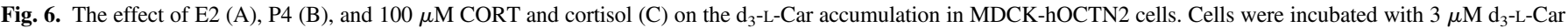

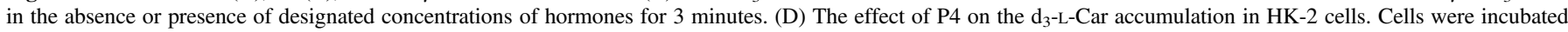

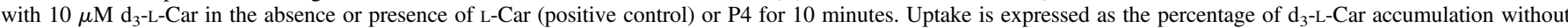
inhibitors. Data are expressed as the mean \pm S.E.M. from two independent experiments conducted in triplicate. Compared with the control, $* * * P<0.001$.

fatty acids in the livers of GD 18 mice is higher than that in nonpregnant mice.

\section{Discussion}

The present study investigated the mechanism of maternal plasma L-Car concentration reduction during pregnancy in mice, and found that OCTN2-mediated L-Car transfer across the placenta played a major role in maternal plasma L-Car reduction, and that the reduction of maternal plasma L-Car level did not induce a decrease in hepatic L-Car concentration and fatty acid $\beta$-oxidation.

Our study found that the plasma concentration of L-Car in GD 18 mice was only $65 \%$ of that in nonpregnant mice (Fig. 1), which was consistent with the results in pregnant and nonpregnant women (Cederblad et al., 1986; Cho and Cha, 2005). We subsequently found that L-Car concentration in fetal plasma was threefold greater than that in maternal plasma of GD 18 mice (Fig. 2A). Although CT1, CT2, OCTN2, and $\mathrm{ATB}^{0,+}$ can mediate L-Car uptake, our results revealed that only Octn2/ OCTN2 mRNA was highly expressed in mouse and human placentas (Fig. 2, B and C), which indicated that OCTN2 might mediate most of the maternal-fetal L-Car transport. And the expression of OCTN2 in the human placenta was upregulated as gestation proceeds (Fig. 2D), which is possibly due to the increased demand of the fetus for L-Car. In addition, although OCTN1 (SLC22A4 gene) is expressed in the placenta and has high homology to OCTN2 (Tamai et al., 1997). However, several published studies showed that human/mouse/rat OCTN1 did not (Wu et al., 2000; Amat di San Filippo et al., 2003) or transported L-Car with a very low capacity (Yabuuchi et al., 1999; Tamai et al., 2000). Our study demonstrated that $\mathrm{d}_{3}$-L-Car was not a substrate of hOCTN1 using the MDCK-hOCTN1 cell model (Supplemental Fig. 1A). Moreover, we found that L-Car concentration in MDCK-hOCTN1 cells was not higher than that in mock cells, whereas the concentration in MDCK-hOCTN2 cells was extremely higher (Supplemental Fig. 1B). Given the above, we considered that OCTN1 played a very limited role in L-Car placental transport. Therefore, we reasoned that OCTN2 located in the brush border membrane of placenta mediated L-Car uptake from maternal circulation, caused maternal plasma L-Car reduction. Future studies will be needed to elucidate how L-Car transports from the placenta to fetal circulation.

The increased renal excretion of L-Car can also lead to the reduction of maternal plasma L-Car. However, our experiment revealed that the urinary excretion of L-Car in pregnant mice during the third trimester was lower than that in nonpregnant and postpartum mice (Fig. 3A). The result is in line with several previous reports (Marzo et al., 1994; Cho and Cha, 2005), in which it was reported that pregnant women had higher urinary excretion of L-Car during the first trimester than that in 


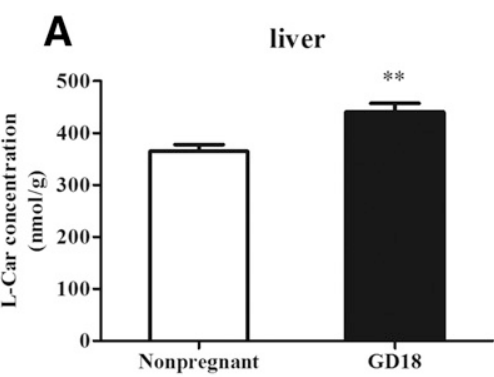

D

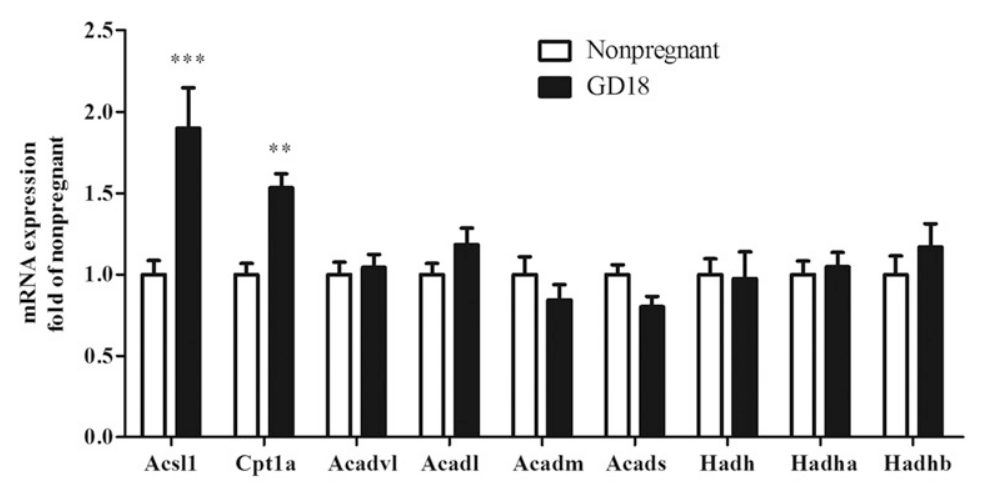

B liver

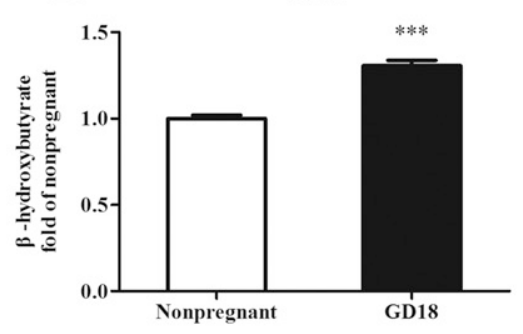

C

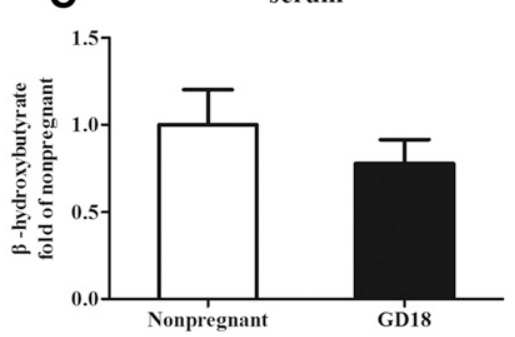

E

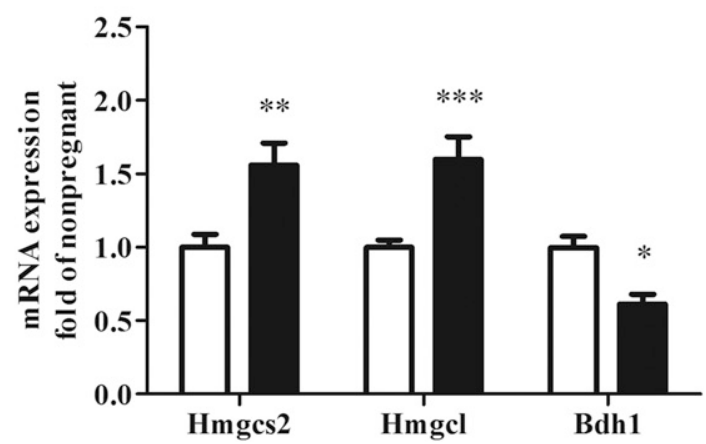

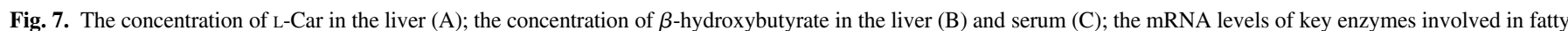

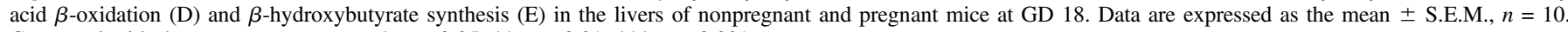
Compared with the nonpregnant group, $* P<0.05$; $* * P<0.01$; $* * * P<0.001$.

nonpregnant or postpartum women, but the excretion was decreased markedly during the third trimester. Therefore, renal excretion of L-Car can be ruled out as a possible reason for the lower plasma L-Car concentration during late pregnancy in mice.

We found that the L-Car concentration and the mRNA level of Octn2 in the kidneys of GD 18 mice were significantly lower than those in nonpregnant mice (Fig. 3, B and C), which means that the renal reabsorption of L-Car in GD 18 mice was decreased. Our results demonstrated that $\mathrm{P} 4$ significantly inhibited the uptake of $\mathrm{d}_{3}$-L-Car in MDCK-hOCTN2 cells and HK-2 cells (Fig. 6, B and D), which is consistent with the previous report that $\mathrm{P} 4$ was a competitive inhibitor of L-Car uptake in BeWo cells (Rytting and Audus, 2008). Furthermore, we found that P4 downregulated the expression of OCTN2 in HK-2 cells through the PPAR $\alpha$-mediated pathway (Fig. 5C). Meanwhile, the mRNA level of Ppar $\alpha$ was obviously lower in the kidneys of GD 18 mice than that in kidneys of nonpregnant mice (Fig. 5E). Thus, the reduction of $\mathrm{L}$-Car reabsorption might be the result of $\mathrm{P} 4$-induced downregulation and activity inhibition of renal OCTN2. In addition, we considered that the reduction of the urinary excretion of L-Car might be due to reduced the glomerular filtration of L-Car because of the decreased maternal plasma L-Car concentration in late pregnancy.

Besides renal excretion and placental transfer, L-Car homeostasis in humans is also maintained by dietary intake and endogenous synthesis. Cho and Cha (2005) reported that pregnant Korean women had lower L-Car intake than nonpregnant women during the first trimester, but that intake increased as gestation proceeded. L-Car biosynthesis involves a complex series of reactions in several tissues. The availability of $\gamma$-butyrobetaine in the liver and kidney is limiting for L-Car biosynthesis in humans (Rebouche et al., 1989). Ringseis et al. (2010) examined plasma samples from 79 pregnant women at delivery and found a positive correlation between plasma concentrations of $\gamma$-butyrobetaine and L-Car; thus, they proposed that low plasma concentration of L-Car in pregnant women might be the result of a diminished L-Car biosynthesis due to the lack of sufficient $\gamma$-butyrobetaine. However, Coşkun and Doğan (2002) found that L-Car biosynthesis in rabbit liver increased gradually in late pregnancy due to increased $\gamma$-butyrobetaine hydroxylase activity. Fernández Ortega (1989) reported that liver L-Car levels were increased during late gestation in rats. There is no report regarding the L-Car biosynthesis alteration in kidney during pregnancy. Therefore, the status of L-Car biosynthesis in human liver and kidney during pregnancy remains to be investigated. In addition, volume dilution caused by plasma volume increase during pregnancy might also contribute to maternal plasma L-Car reduction.

Based on the above considerations, we think that the reasons for the plasma L-Car concentration decrease in women during pregnancy are complicated. The reduction of plasma L-Car concentration in pregnant women during the first trimester might be due to dietary intake reduction and urinary excretion increase, and the reduction during the third trimester might be mainly attributed to placental transfer increase as well as volume dilution.

Because L-Car plays an important role in fatty acid $\beta$-oxidation, it is reasonable to be speculated that plasma L-Car concentration reduction during pregnancy might lead to a decrease in $\beta$-oxidation and a rise in plasma lipids. However, the hepatic level of $\beta$-hydroxybutyrate was significantly higher in GD 18 mice than that in nonpregnant mice (Fig. 7B), which means that the $\beta$-oxidation of fatty acids in the livers of GD 18 mice was higher than that of nonpregnant mice. We considered that it might be due to the increased expression of long-chain acyl-CoA synthetase 1 , carnitine palmitoyltransferase 1a, hydroxymethyl glutarylCoA synthase, and hydroxymethyl glutaryl-CoA lyase, and to the higher concentration of L-Car in the livers of GD 18 mice (Fig. 7, A, D, and E). On the other hand, L-Car level in the hearts of GD 18 mice was lower than that in the hearts of nonpregnant mice, while no difference was found in the muscle (Supplemental Fig. 2). Nevertheless, Liu et al. (2017) found that fatty acid uptake and oxidation in the heart of late pregnant mice were increased. Taken together, we considered that decreased 
plasma L-Car levels might not be responsible for elevated plasma TG and TC levels in pregnancy. Since elevated TG levels throughout pregnancy have been shown to increase the risk of adverse pregnancy outcomes, including gestational diabetes mellitus, preeclampsia, and preterm birth (Spracklen et al., 2014; Ryckman et al., 2015; Zheng et al., 2018), the mechanisms of plasma TG and TC rise during pregnancy are already under study in our laboratory.

It is unknown whether such low L-Car concentrations in pregnant women will induce adverse consequences. Nevertheless, it is possible that a higher L-Car status could have beneficial effects on pregnant women and their fetuses due to the important functions of L-Car. Thus, a strict vegetarian diet should be avoided during pregnancy because vegetables contain much less L-Car than meat and fish (Pochini et al., 2019). It has been reported that L-Car supplementation can prevent the marked decrease of plasma L-Car concentration and the striking increase of plasma free fatty acids in pregnant women (Keller et al., 2009). However, it remains unknown whether supplementation of L-Car will reduce plasma TG and TC in pregnant women, which needs further study.

In conclusion, our results confirmed that maternal plasma L-Car concentration was reduced in pregnancy, which was mainly attributed to placental transfer of L-Car mediated by OCTN2 but not to renal excretion increase, and that OCTN2 was upregulated as gestation proceeded in human placenta. Unexpectedly, the reduction of maternal plasma L-Car levels did not induce a decrease in hepatic L-Car concentrations and fatty acid $\beta$-oxidation in mice; thus, it was not the main cause of the rise in plasma lipid levels during pregnancy.

\section{Acknowledgments}

We thank Haihong Hu (Institute of Drug Metabolism and Pharmaceutical Analysis, Zhejiang University) for managing the instruments and helping with experiments.

\section{Authorship Contributions}

Participated in research design: Bai, Sun, Zheng, S. Zeng, and Jiang.

Conducted experiments: Bai, Q. Zeng, Y. Chen, M. Chen, and Li.

Performed data analysis: Bai, Ma, Zhou, and Jiang.

Wrote or contributed to the writing of the manuscript: Bai, Q. Zeng, and Jiang.

\section{References}

Alemu A, Abebe M, Biadgo B, Terefe B, and Baynes HW (2018) Biochemical profiles of pregnant and non-pregnant women attending at the University of Gondar Hospital, Northwest Ethiopia: a comparative cross-sectional study. Ethiop J Health Sci 28:331-340.

Amat di San Filippo C, Wang Y, and Longo N (2003) Functional domains in the carnitine transporter OCTN2, defective in primary carnitine deficiency. J Biol Chem 278:47776-47784.

Bai M, Ma Z, Sun D, Zheng C, Weng Y, Yang X, Jiang T, and Jiang H (2017) Multiple drug transporters mediate the placental transport of sulpiride. Arch Toxicol 91:3873-3884.

Cederblad G, Fåhraeus L, and Lindgren K (1986) Plasma carnitine and renal-carnitine clearance during pregnancy. Am J Clin Nutr 44:379-383.

Cho SW and Cha YS (2005) Pregnancy increases urinary loss of carnitine and reduces plasma carnitine in Korean women. Br J Nutr 93:685-691.

Coşkun A and Doğan M (2002) Liver L-carnitine biosynthesis in non-pregnant, pregnant and lactating rabbits. Res Commun Mol Pathol Pharmacol 111:211-223.

Costantine MM (2014) Physiologic and pharmacokinetic changes in pregnancy. Front Pharmacol 5:65

D’Argenio G, Petillo O, Margarucci S, Torpedine A, Calarco A, Koverech A, Boccia A, Paolella G, and Peluso G (2010) Colon OCTN2 gene expression is up-regulated by peroxisome proliferatoractivated receptor gamma in humans and mice and contributes to local and systemic carnitine homeostasis. J Biol Chem 285:27078-27087.

Enomoto A, Wempe MF, Tsuchida H, Shin HJ, Cha SH, Anzai N, Goto A, Sakamoto A, Niwa T, Kanai Y, et al. (2002) Molecular identification of a novel carnitine transporter specific to human testis. Insights into the mechanism of carnitine recognition. J Biol Chem 277:36262-36271.

Fernández Ortega MF (1989) Effect of dietary lysine level and protein restriction on the lipids and carnitine levels in the liver of pregnant rats. Ann Nutr Metab 33:162-169.

Foster DW (2004) The role of the carnitine system in human metabolism. Ann N Y Acad Sci 1033: $1-16$

Frigeni M, Balakrishnan B, Yin X, Calderon FRO, Mao R, Pasquali M, and Longo N (2017) Functional and molecular studies in primary carnitine deficiency. Hum Mutat 38:1684-1699.
Grube M, Meyer Zu Schwabedissen H, Draber K, Präger D, Möritz KU, Linnemann K, Fusch C, Jedlitschky G, and Kroemer HK (2005) Expression, localization, and function of the carnitine transporter octn2 (slc22a5) in human placenta. Drug Metab Dispos 33:31-37.

Hahn P (1981) The development of carnitine synthesis from gamma-butyrobetaine in the rat. Life Sci 28:1057-1060.

Jung C, Ho JT, Torpy DJ, Rogers A, Doogue M, Lewis JG, Czajko RJ, and Inder WJ (2011) A longitudinal study of plasma and urinary cortisol in pregnancy and postpartum. $J$ Clin Endocrinol Metab 96:1533-1540.

Keller U, van der Wal C, Seliger G, Scheler C, Röpke F, and Eder K (2009) Carnitine status of pregnant women: effect of carnitine supplementation and correlation between iron status and plasma carnitine concentration. Eur J Clin Nutr 63:1098-1105.

Lahjouji K, Elimrani I, Lafond J, Leduc L, Qureshi IA, and Mitchell GA (2004) L-carnitine transport in human placental brush-border membranes is mediated by the sodium-dependent organic cation transporter OCTN2. Am J Physiol Cell Physiol 287:C263-C269.

Lahjouji K, Elimrani I, Wu J, Mitchell GA, and Qureshi IA (2002) A heterozygote phenotype is present in the jvs +/- mutant mouse livers. Mol Genet Metab 76:76-80.

La Marca A, Giulini S, Orvieto R, De Leo V, and Volpe A (2005) Anti-Müllerian hormone concentrations in maternal serum during pregnancy. Hum Reprod 20:1569-1572.

Layton J, Powe C, Allard C, Battista MC, Doyon M, Bouchard L, Perron P, Wessel J, and Hivert MF (2019) Maternal lipid profile differs by gestational diabetes physiologic subtype. Metabolism 91:39-42.

Li L, Weng Y, Wang W, Bai M, Lei H, Zhou H, and Jiang H (2017) Multiple organic cation transporters contribute to the renal transport of sulpiride. Biopharm Drug Dispos 38: 526-534.

Lindsay KL, Hellmuth C, Uhl O, Buss C, Wadhwa PD, Koletzko B, and Entringer S (2015) Longitudinal metabolomic profiling of amino acids and lipids across healthy pregnancy. PLoS One 10:e145794.

Liu LX, Rowe GC, Yang S, Li J, Damilano F, Chan MC, Lu W, Jang C, Wada S, Morley M, et al (2017) PDK4 inhibits cardiac pyruvate oxidation in late pregnancy. Circ Res 121:1370-1378.

Longo N, Frigeni M, and Pasquali M (2016) Carnitine transport and fatty acid oxidation. Biochim Biophys Acta 1863:2422-2435.

Luo H, Zhang Y, Guo H, Zhang L, Li X, Ringseis R, Wen G, Hui D, Liang A, Eder K, et al. (2014) Transcriptional regulation of the human, porcine and bovine OCTN2 gene by PPAR $\alpha$ via a conserved PPRE located in intron 1. BMC Genet 15:90.

Luo J, Qu J, Yang R, Ge MX, Mei Y, Zhou BT, and Qu Q (2016) Phytochemicals mediate the expression and activity of OCTN2 as activators of the PPAR $\gamma / \operatorname{RXR} \alpha$ pathway. Front Pharmacol 7:189.

Ma Z, Yang X, Jiang T, Bai M, Zheng C, Zeng S, Sun D, and Jiang H (2017) Multiple SLC and ABC transporters contribute to the placental transfer of entecavir. Drug Metab Dispos 45: 269-278.

Marzo A, Cardace G, Corbelletta C, Pace S, D'Iddio S, Verrotti C, Cavatorta E, and Grignaffini A (1994) Plasma concentration, urinary excretion and renal clearance of L-carnitine during pregnancy: a reversible secondary L-carnitine deficiency. Gynecol Endocrinol 8:115-120.

Nakanishi T, Hatanaka T, Huang W, Prasad PD, Leibach FH, Ganapathy ME, and Ganapathy V (2001) Na+- and Cl--coupled active transport of carnitine by the amino acid transporter ATB $(0,+)$ from mouse colon expressed in HRPE cells and Xenopus oocytes. $J$ Physiol 532: 297-304.

Pecks U, Rath W, Kleine-Eggebrecht N, Maass N, Voigt F, Goecke TW, Mohaupt MG, and Escher G (2016) Maternal serum lipid, estradiol, and progesterone levels in pregnancy, and the impact of placental and hepatic pathologies. Geburtshilfe Frauenheilkd 76:799-808.

Pochini L, Galluccio M, Scalise M, Console L, and Indiveri C (2019) OCTN: a small transporter subfamily with great relevance to human pathophysiology, drug discovery, and diagnostics. SLAS Discov 24:89-110.

Ramsay RR, Gandour RD, and van der Leij FR (2001) Molecular enzymology of carnitine transfer and transport. Biochim Biophys Acta 1546:21-43.

Rebouche CJ, Bosch EP, Chenard CA, Schabold KJ, and Nelson SE (1989) Utilization of dietary precursors for carnitine synthesis in human adults. J Nutr 119:1907-1913.

Ringseis R, Hanisch N, Seliger G, and Eder K (2010) Low availability of carnitine precursors as a possible reason for the diminished plasma carnitine concentrations in pregnant women. BMC Pregnancy Childbirth 10:17.

Ryckman KK, Spracklen CN, Smith CJ, Robinson JG, and Saftlas AF (2015) Maternal lipid levels during pregnancy and gestational diabetes: a systematic review and meta-analysis. BJOG 122: 643-651.

Rytting E and Audus KL (2008) Contributions of phosphorylation to regulation of OCTN2 uptake of carnitine are minimal in BeWo cells. Biochem Pharmacol 75:745-751.

Sekine T, Kusuhara H, Utsunomiya-Tate N, Tsuda M, Sugiyama Y, Kanai Y, and Endou H (1998) Molecular cloning and characterization of high-affinity carnitine transporter from rat intestine. Biochem Biophys Res Commun 251:586-591.

Shenai JP and Borum PR (1984) Tissue carnitine reserves of newborn infants. Pediatr Res 18: 679-682.

Soldin OP, Guo T, Weiderpass E, Tractenberg RE, Hilakivi-Clarke L, and Soldin SJ (2005) Steroid hormone levels in pregnancy and 1 year postpartum using isotope dilution tandem mass spectrometry. Fertil Steril 84:701-710.

Spracklen CN, Smith CJ, Saftlas AF, Robinson JG, and Ryckman KK (2014) Maternal hyperlipidemia and the risk of preeclampsia: a meta-analysis. Am J Epidemiol 180:346-358.

Talián GC, Komlósi K, Decsi T, Koletzko B, and Melegh B (2007) Determination of carnitine ester patterns during the second half of pregnancy, at delivery, and in neonatal cord blood by tandem mass spectrometry: complex and dynamic involvement of carnitine in the intermediary metabolism. Pediatr Res 62:88-92.

Tamai I, Ohashi R, Nezu JI, Sai Y, Kobayashi D, Oku A, Shimane M, and Tsuji A (2000) Molecular and functional characterization of organic cation/carnitine transporter family in mice. J Biol Chem 275:40064-40072.

Tamai I, Yabuuchi H, Nezu J, Sai Y, Oku A, Shimane M, and Tsuji A (1997) Cloning and characterization of a novel human $\mathrm{pH}$-dependent organic cation transporter, OCTN1. FEBS Lett 419:107-111

Vaz FM and Wanders RJ (2002) Carnitine biosynthesis in mammals. Biochem J 361:417-429.

Wang C, Kong L, Yang Y, Wei Y, Zhu W, Su R, Lin L, and Yang H (2018) Recommended reference values for serum lipids during early and middle pregnancy: a retrospective study from China. Lipids Health Dis 17:246. 
Wang W, Bai M, Jiang T, Li C, Li P, Zhou H, Wang Z, Li L, and Jiang H (2019) Clozapineinduced reduction of l-carnitine reabsorption via inhibition/down-regulation of renal carnitine/ organic cation transporter 2 contributes to liver lipid metabolic disorder in mice. Toxicol Appl Pharmacol 363:47-56.

Winter SC, Linn LS, and Helton E (1995) Plasma carnitine concentrations in pregnancy, cord blood, and neonates and children. Clin Chim Acta 243:87-93.

Wu X, George RL, Huang W, Wang H, Conway SJ, Leibach FH, and Ganapathy V (2000) Structural and functional characteristics and tissue distribution pattern of rat OCTN1, an organic cation transporter, cloned from placenta. Biochim Biophys Acta 1466 $315-327$.

Yabuuchi H, Tamai I, Nezu J, Sakamoto K, Oku A, Shimane M, Sai Y, and Tsuji A (1999) Novel membrane transporter OCTN1 mediates multispecific, bidirectional, and pH-dependent transport of organic cations. J Pharmacol Exp Ther 289:768-773.
Zhang Z, Farooq M, Prasad B, Grepper S, and Unadkat JD (2015) Prediction of gestational age-dependent induction of in vivo hepatic CYP3A activity based on HepaRG cells and human hepatocytes. Drug Metab Dispos 43:836-842.

Zheng W, Huang W, Zhang L, Tian Z, Wang T, Zhang T, Zhang Z, Zhang W, and Li G (2018) Changes in serum lipid levels during pregnancy and association with neonatal outcomes: a large cohort study. Reprod Sci 25:1406-1412.

Address correspondence to: Huidi Jiang, College of Pharmaceutical Sciences, Zhejiang University, 866 Yuhangtang Road, Zijingang Campus, Hangzhou 310058, People's Republic of China. E-mail: hdjiang@zju.edu.cn 